\title{
Frequencies of MNS Blood Group Antigens and Phenotypes in Southwestern Saudi Arabia
}

\author{
Amr J Halawani (iD) \\ Mahmoud M Habibullah (iD) ${ }^{2,3}$ \\ Gasim Dobie (D) ${ }^{2}$ \\ Alaa Alhazmi ${ }^{2,3}$ \\ Farkad Bantun ${ }^{4}$ \\ Mohammed H Nahari ${ }^{5}$ \\ Ibrahim Dawmary ${ }^{6}$ \\ Hisham I Abu-Tawil ${ }^{6,7}$ \\ 'Department of Laboratory Medicine, \\ Faculty of Applied Medical Sciences, \\ Umm Al-Qura University, Makkah, Saudi \\ Arabia; ${ }^{2}$ Department of Medical \\ Laboratory Technology, Faculty of \\ Applied Medical Sciences, Jazan \\ University, Jazan, Saudi Arabia; ${ }^{3}$ SMIRES \\ for Consultation in Specialized Medical \\ Laboratories, Jazan University, Jazan, \\ Saudi Arabia; ${ }^{4}$ Department of \\ Microbiology, Faculty of Medicine, Umm \\ Al-Qura University, Makkah, Saudi \\ Arabia; ${ }^{5}$ Department of Clinical \\ Laboratory Sciences, College of Applied \\ Medical Sciences, Najran University, \\ Najran, Saudi Arabia; ${ }^{6}$ Department of \\ Laboratory and Blood Bank, Prince \\ Mohammed bin Nasser Hospital, Ministry \\ of Health, Jazan, Saudi Arabia; \\ ${ }^{7}$ Department of Laboratory and Blood \\ Bank, King Faisal Medical City for \\ Southern Regions, Ministry of Health, \\ Abha, Saudi Arabia
}

Purpose: Knowledge of the prevalence of blood group antigens in a given population is important for the prevention of hemolytic reactions. The MNS blood group system (002) has four polymorphic antigens-M, N, S, and s. Anti-S and anti-s antibodies may result in immediate and delayed hemolytic transfusion reactions, and hemolytic disease of the fetus and newborn may occur. The present study investigated the frequencies of the main antigens and phenotypes of the MNS blood group system.

Subjects and Methods: We randomly obtained 149 samples from anonymous Saudi blood donors living in Jazan Province. Serotyping was conducted using a gel card to investigate (M, N, S, and s) antigens and phenotypes.

Results: The frequencies of MNS antigens were as follows: $\mathrm{M}=89.26 \%, \mathrm{~N}=51.67 \%, \mathrm{~S}=$ $61.07 \%$, and $\mathrm{s}=82.55 \%$. Regarding the MNS phenotypes, nine phenotypes were observed in the study population. The most common phenotype was $\mathrm{M}+\mathrm{N}-\mathrm{S}+\mathrm{s}+(\mathrm{n}=36,24.16 \%)$, in contrast to the least common phenotype $\mathrm{M}+\mathrm{N}-\mathrm{S}-\mathrm{S}-(\mathrm{n}=1,0.67 \%)$. The prevalence of the MNS phenotypes in the current study population was highly and significantly different from that in Europeans $(P=0.044)$ and African Americans $(P=0.000)$.

Conclusion: In summary, this study reports the frequencies of the MNS antigens and phenotypes in Jazan Province, Saudi Arabia. The most common phenotype was $\mathrm{M}+\mathrm{N}-$ $\mathrm{S}+\mathrm{S}^{+}$, whereas the least observed phenotype was $\mathrm{M}+\mathrm{N}-\mathrm{S}-\mathrm{S}-$. The outcomes of this study may assist the blood banks in Jazan Province to establish an extended phenotyping protocol including the MNS antigens, in particular S and s antigens, to preclude any alloimmunization events.

Keywords: MNS blood group, blood donors, transfusion, Saudi Arabia

\section{Introduction}

Following the discovery of the ABO blood group system, Landsteiner and Levine identified the first two antigens of the MNS blood group system, the $M$ and $\mathrm{N}$ antigens. ${ }^{1}$ This is the second and most complex blood group system discovered, after the RH system, comprising 50 antigens. ${ }^{2}$ Interestingly, it is the only system that is represented by three homologous genes, GYPA, GYPB, and GYPE. ${ }^{3}$ The antigens of the MNS system are completely expressed at birth and are carried on two carrier molecules, glycophorin A (GPA) and glycophorin B (GPB). GPA carries the $\mathrm{M}$ and $\mathrm{N}$ antigens, whereas GPB carries the $\mathrm{S}$ and $\mathrm{s}$ antigens. ${ }^{4}$

The most abundant red cell sialoglycoprotein is GPA, with a copy number per red cell of approximately $1 \times 10^{6} .^{5}$ In contrast to O-glycans that are observed in the amino termini of both GPA and GPB, N-glycan is found exclusively on GPA in an amino acid (asparagine) at position $26 .^{6}$ However, the O-glycans carry most of the sialic
Correspondence: Amr J Halawan Makkah, 2438I 8I56, Saudi Arabia Email ajjhalawani@uqu.edu.sa 
acids that are found on the red cells, which contribute to the net negative charge that prevents the red cells from sticking to each other. In addition, it precludes the adherence of the red cells to the endothelial cells of the blood vessels. ${ }^{7}$ The negatively charged glycocalyx "cell coat" shields the red cells from invasion by foreign pathogens. ${ }^{8,9}$

GPA deficiency in the red cells makes them more resistant to invasion by the malarial parasite Plasmodium falciparum due to the reduced level of sialic acid, which appears to be vital for parasitic adherence to the red cells. ${ }^{10-12}$ Moreover, there is evidence that the influenza virus and the encephalomyocarditis virus target the sialic acid attached to GPA and GPB. ${ }^{8,13}$ Furthermore, both GPA and GPB act as chaperones for band 3 transport to red cell membrane. ${ }^{14}$

The anti-M and anti- $\mathrm{N}$ antibodies are clinically benign because they are naturally occurring IgM antibodies, and this can be neglected in the transfusion practice if they react at $37^{\circ} \mathrm{C}$. A few cases of anti-M and anti-N causing hemolytic transfusion reactions (HTR) have been reported in addition to cases of hemolytic disease of the fetus and newborn (HDFN). ${ }^{15}$ Anti-S, anti-s, and anti-U are IgG antibodies and have been found to be involved in both immediate and delayed HTR and HDFN. HDFN is reportedly caused by many low-prevalence MNS antibodies, and this is typically the method by which they are discovered. HTR can be caused by allo-anti-En ${ }^{\mathrm{a}}$, whereas fatal and severe autoimmune hemolytic anemia can be caused by auto-anti-En ${ }^{\text {a }}{ }^{16-18}$

Reports on the frequencies of MNS antigens and phenotypes vary from one ethnicity to another. ${ }^{19-21}$ In the Kingdom of Saudi Arabia, a single study, which was conducted in the Eastern Province of Saudi Arabia, reported the frequencies of the MNS antigens and their relevant phenotypes. ${ }^{22}$ The Jazan Province is an area where sickle cell disease and thalassemia are endemic. $^{23,24}$ Therefore, to preclude the risk of alloimmunization, it is crucial to determine the frequency of the antigens for such patients, who are dependent on blood transfusion and receive multiple blood units. ${ }^{25}$

This study aimed to investigate the frequencies of the MNS blood group system (M, N, S, and s) antigens among Saudi blood donors in Jazan Province, southwestern Saudi Arabia. Furthermore, the phenotypes of this system were determined.

\section{Materials and Methods Blood Samples}

We collected 149 blood samples in ethylenediaminetetraacetate tubes. The study was conducted in Jazan Province,
Saudi Arabia, between March 2021 and August 2021. This study was approved by Jazan Hospital Institutional Review Board (NO. 2017). The samples were obtained from anonymous Saudi citizens living in Jazan Province. They voluntarily donated blood at the blood bank of Prince Muhammad bin Nasser Hospital after signing a consent form and completing the donation card prior to blood donation.

\section{Immunohematology}

Serotyping was carried out using a commercial kit based on the gel card technology ID card antigen profile-III (M, N, S, s, Fya, Fyb), following the manufacturer's instructions (DiaMed GmBH, Cressier, Switzerland). A 0.8\% red cell suspension was prepared by mixing $1.0 \mathrm{~mL}$ of IDDiluent 2 (DiaMed GmBH) with $20 \mu \mathrm{L}$ of whole blood. A total of $50 \mu \mathrm{L}$ of $0.8 \%$ red cell suspension was added to all microwells of the gel card, followed by the addition of $50 \mu \mathrm{L}$ of ID-test sera to the appropriate microwells. The specimens were then incubated at room temperature for 10 min followed by centrifugation at $85 \times \mathrm{g}$ in the IDCentrifuge (DiaMed GmBH).

\section{Interpretation of Results}

A pellet at the bottom of the microwells resulting from the reaction indicated a negative result and the absence of the relevant antigen. Conversely, a positive result, graded $(1+$, $2+, 3+$, and $4+$ ) depending on the strength of the reaction, forming a distinct red line or cell diffusion, indicated the presence of the corresponding antigen.

\section{Statistical Analyses}

The sample size was calculated as in our previously published work. ${ }^{26}$ The prevalence of the MNS antigens as well as phenotypes were presented and standardized as a percentage. To compare the frequencies of phenotypes in the Jazani population with those in the other ethnicities, a chi-squared test was performed. $P$-values $<0.05$ and $<0.01$ indicated significant and highly significant differences, respectively.

\section{Results}

We investigated 149 samples for determining the frequencies of antigens and phenotypes of the MNS blood group system. Table 1 presents the prevalence of the MNS antigens among the Saudi blood donors living in Jazan Province, Saudi Arabia. The M antigen was the most prevalent antigen observed among 133 (89.26\%) samples, whereas the $\mathrm{N}$ antigen was the least prevalent antigen and was found 
Table I The Frequencies of MNS Blood Group Antigens in Jazan Province, Saudi Arabia

\begin{tabular}{|l|l|l|}
\hline Antigen & Observation (n) & Frequency (\%) \\
\hline M & 133 & 89.26 \\
N & 77 & 51.67 \\
S & 91 & 61.07 \\
S & 123 & 82.55 \\
\hline
\end{tabular}

only in 77 samples $(51.67 \%)$. The frequencies of the $\mathrm{S}$ and $\mathrm{s}$ antigens were $91(61.07 \%)$ and $123(82.55 \%)$, respectively.

Nine phenotypes were observed in the Jazani population. Table 2 demonstrates the prevalence of the MNS phenotypes. The most common phenotype of the MNS blood group was $\mathrm{M}+\mathrm{N}-\mathrm{S}+\mathrm{s}+(\mathrm{n}=36,24.16 \%)$, compared with the least common phenotype $\mathrm{M}+\mathrm{N}-\mathrm{S}-\mathrm{S}-(\mathrm{n}=1$, $0.67 \%$ ). Two phenotypes, $\mathrm{M}+\mathrm{N}+\mathrm{S}+\mathrm{s}+$ and $\mathrm{M}+\mathrm{N}+\mathrm{S}-\mathrm{s}+$, had the same prevalence $(n=24,16.12 \%$ each). The phenotype $\mathrm{M}+\mathrm{N}-\mathrm{S}-\mathrm{S}+$ was found in 23 (15.43\%) individuals, whereas the phenotype $\mathrm{M}-\mathrm{N}+\mathrm{S}+\mathrm{s}+$ was found only in $6(4.02 \%)$ individuals. Three phenotypes were not observed in the present study, including $\mathrm{M}+\mathrm{N}+\mathrm{S}-\mathrm{S}-, \mathrm{M}-$ $\mathrm{N}+\mathrm{S}+\mathrm{s}-$, and $\mathrm{M}-\mathrm{N}+\mathrm{S}-\mathrm{S}-$. Table 3 shows a comparison of the phenotype frequencies between the different local ethnic groups in Saudi Arabia and worldwide.

\section{Discussion}

Knowledge of the frequencies of blood group antigens and phenotypes is essential in transfusion practice. This may help reduce the risk of alloimmunization, especially in

Table 2 Frequencies of MNS Phenotypes in Jazan Province, Saudi Arabia

\begin{tabular}{|l|l|l|}
\hline Phenotype & Observation (n) & Frequency (\%) \\
\cline { 3 - 3 } & & $\mathbf{n}=149$ \\
\hline$M+N-S+s-$ & 12 & 8.05 \\
$M+N-S+s+$ & 36 & 24.16 \\
$M+N-S-s^{+}$ & 23 & 15.43 \\
$M+N-S-s-$ & 1 & 0.67 \\
$M+N+S+s-$ & 13 & 8.72 \\
$M+N+S+s+$ & 24 & 16.12 \\
$M+N+S-s+$ & 24 & 16.12 \\
$M+N+S-s-$ & 0 & 0 \\
$M-N+S+s-$ & 0 & 0 \\
$M-N+S-s+$ & 10 & 6.71 \\
$M-N+S-s-$ & 0 & 0 \\
$M-N+S+s+$ & 6 & 4.02 \\
Total & 149 & $100 \%$ \\
\hline
\end{tabular}

transfusion-dependent patients, by aiding the selection of compatible blood units. $^{27}$

Previous studies reported the frequencies of $\mathrm{ABO}, \mathrm{RH}$, KEL1, Duffy, and Kidd blood groups among Saudi blood donors in Jazan Province. ${ }^{26,28,29}$

In the present study, we investigated the frequencies of MNS antigens in Saudi blood donors living in Jazan Province. The gel card technology was used to analyze the MNS antigens because it is a simple, reproducible, and cost-effective test, which is not labor-intensive. ${ }^{30}$

The prevalence of the antigens in the present study was as follows: $\mathrm{M}$ antigen (89.26\%), N (51.67\%), S (61.07\%), and $\mathrm{s}(82.55 \%)$. Interestingly, these observations were relatively similar to the frequencies in the Eastern Province of Saudi Arabia. Owaidah et al reported the frequencies of the MNS antigens as follows: $M$ antigen $(87 \%), \mathrm{N}(52 \%), \mathrm{S}(59 \%)$, and $\mathrm{s}(83 \%){ }^{22}$ These similarities are noteworthy, although there may be geographical variations and ethnic background differences between the individuals of Jazan Province and Eastern Province. However, the frequencies of some phenotypes were different.

Regarding the MNS phenotypes, nine phenotypes were found in the Jazani population. The most common phenotype was $\mathrm{M}+\mathrm{N}-\mathrm{S}+\mathrm{s}+(24.16 \%)$. A study in the Eastern Province reported a similar finding that this phenotype was the most common (24\%). ${ }^{22}$ The frequency of this phenotype was considered to be high in the present study compared to that in Europeans $(14 \%, P<0.05)$, African Americans $(7 \%, P<0.01)$, and Indians $(14.8 \%) .{ }^{19-21}$ Conversely, the least observed phenotype in the Jazani population was $\mathrm{M}+\mathrm{N}-\mathrm{S}-\mathrm{s}-(0.67 \%)$. This phenotype was previously exclusively found in African Americans $(0.4 \%){ }^{20}$ Indeed, there was a highly statistically significant difference between the frequencies of MNS phenotypes in the Jazani population compared to that in African Americans $(P<0.01)$ [Table 3]. This may reflect the immigration of some tribes of Africa who have lived in Jazan Province many years ago.

Many variations were observed between the frequencies of the phenotypes in the Jazani population when compared with those in Europeans $(P<0.05)$ [Table 3]. The frequencies of some phenotypes were relatively similar in the present study compared with the findings in the Eastern Province. $^{22}$ These include the frequencies of $\mathrm{M}$ $+\mathrm{N}-\mathrm{S}-\mathrm{S}+, \quad \mathrm{M}+\mathrm{N}+\mathrm{S}+\mathrm{s}+, \quad \mathrm{M}-\mathrm{N}+\mathrm{S}-\mathrm{S}+$, and $\mathrm{M}-\mathrm{N}+\mathrm{S}+\mathrm{s}+$. Interestingly, the frequency of the phenotype $\mathrm{M}+\mathrm{N}-\mathrm{S}-\mathrm{s}+$ observed in the present study $(15.43 \%)$ was very similar to 
Table 3 MNS Phenotype Frequencies in the Jazan Province Among Different Ethnicities

\begin{tabular}{|c|c|c|c|c|c|}
\hline \multirow[t]{2}{*}{ Phenotype } & $\begin{array}{l}\text { Jazan Province (Saudi } \\
\text { Arabia) (\%) }\end{array}$ & $\begin{array}{l}\text { Eastern Province (Saudi } \\
\text { Arabia) }(\%)^{22}\end{array}$ & White (\%) ${ }^{19}$ & African American (\%) & Indian (\%) ${ }^{21}$ \\
\hline & $n=149$ & $n=100$ & $n=1000$ & $n=1322$ & $n=317$ \\
\hline $\mathrm{M}+\mathrm{N}-\mathrm{S}+\mathrm{s}-$ & 8.05 & 11 & 5.7 & 2.1 & 7.9 \\
\hline $\mathrm{M}+\mathrm{N}-\mathrm{S}+\mathrm{s}+$ & 24.16 & 24 & 14 & 7 & 14.8 \\
\hline $\mathrm{M}+\mathrm{N}-\mathrm{S}-\mathrm{s}+$ & 15.43 & 13 & 10.1 & 15.5 & 15.8 \\
\hline $\mathrm{M}+\mathrm{N}-\mathrm{S}-\mathrm{s}-$ & 0.67 & 0 & 0 & 0.4 & 0 \\
\hline $\mathrm{M}+\mathrm{N}+\mathrm{S}+\mathrm{s}-$ & 8.72 & 3 & 3.9 & 2.2 & 3.47 \\
\hline $\mathrm{M}+\mathrm{N}+\mathrm{S}+\mathrm{s}+$ & 16.12 & 15 & 22.4 & 13 & 19.55 \\
\hline $\mathrm{M}+\mathrm{N}+\mathrm{S}-\mathrm{s}+$ & 16.12 & 21 & 22.6 & 33.4 & 13.88 \\
\hline$M+N+S-s-$ & 0 & 0 & 0 & 0.4 & 0 \\
\hline $\mathrm{M}-\mathrm{N}+\mathrm{S}+\mathrm{s}-$ & 0 & 3 & 0.3 & 1.6 & 1.26 \\
\hline $\mathrm{M}-\mathrm{N}+\mathrm{S}-\mathrm{s}^{+}$ & 6.71 & 7 & 15.6 & 19.2 & 13.88 \\
\hline $\mathrm{M}-\mathrm{N}+\mathrm{S}-\mathrm{s}-$ & 0 & 0 & 0 & 0.7 & 0 \\
\hline $\mathrm{M}-\mathrm{N}+\mathrm{S}+\mathrm{s}+$ & 4.02 & 3 & 5.4 & 4.5 & 9.46 \\
\hline \multicolumn{2}{|l|}{$P$-values ${ }^{\S}$} & $\begin{array}{l}\text { Jazan/Eastern } \\
P=0.53(>0.05)\end{array}$ & $\begin{array}{l}\text { Jazan/White } \\
P=0.044 \\
(<0.05)^{*}\end{array}$ & $\begin{array}{l}\text { Jazan/African American } \\
P=0.000(<0.01)^{\S}\end{array}$ & $\begin{array}{l}\text { Jazan/Indian } \\
P=0.212 \\
(>0.05)\end{array}$ \\
\hline
\end{tabular}

Notes: *Significant. ${ }^{\S}$ Highly significant.

that in African Americans (15.5\%) and Indians $(15.8 \%)^{20,21}$

\section{Conclusion}

In conclusion, the frequencies of the MNS antigens were determined. Furthermore, nine phenotypes were identified in the Jazan Province of Saudi Arabia, among which the most prevalent one was $\mathrm{M}+\mathrm{N}-\mathrm{S}+\mathrm{s}+$. This study may assist the blood banks in Jazan Province to establish extended phenotyping for transfusion-dependent patients and include the MNS antigens, in particular the $\mathrm{S}$ and $\mathrm{s}$ antigens, for best transfusion practices.

\section{Ethics Approval and Informed Consent}

Every blood donor provided a written informed consent for participation in this study. This study was approved by Jazan Hospital Institutional Review Board (NO. 2017).

\section{Author Contributions}

All authors made a significant contribution to the work reported, whether that is in the conception, study design, execution, acquisition of data, analysis and interpretation, or in all these areas; took part in drafting, revising or critically reviewing the article; gave final approval of the version to be published; have agreed on the journal to which the article has been submitted; and agree to be accountable for all aspects of the work.

\section{Disclosure}

The authors have no conflicts of interest to declare.

\section{References}

1. Landsteiner K, Levine P. Further observations on individual differences of human blood. Proc Soc Exp Biol Med. 1927;24(9):941-942. doi:10.3181/00379727-24-3649

2. Daniels GL, Fletcher A, Garratty G, et al. Blood group terminology 2004: from the International Society of Blood Transfusion committee on terminology for red cell surface antigens. Vox Sang. 2004;87 (4):304-316. doi:10.1111/j.1423-0410.2004.00564.x

3. Lögdberg L, Reid ME, Lamont RE, Zelinski T. Human blood group genes 2004: chromosomal locations and cloning strategies. Transfus Med Rev. 2005;19(1):45-57. doi:10.1016/j.tmrv.2004.09.007

4. Daniels G. MNS blood group system. In: Human Blood Groups. 3rd ed. Wiley-Blackwell; 2013:96-161. doi:10.1002/9781118493595.ch3

5. Gardner B, Parsons SF, Merry AH, Anstee DJ. Epitopes on sialoglycoprotein alpha: evidence for heterogeneity in the molecule. Immunology. 1989;68(2):283-289.

6. Anstee DJ. The nature and abundance of human red cell surface glycoproteins. J Immunogenet. 1990;17(4-5):219-225. doi:10.1111/ j.1744-313X.1990.tb00875.x

7. Blanchard D. Human red cell glycophorins: biochemical and antigenic properties. Transfus Med Rev. 1990;4(3):170-186. doi:10.1016/S08877963(90) $70263-5$

8. Lublin DM. Functional roles of blood group antigens. In: Molecular and Functional Aspects of Blood Group Antigens. Bethesda, MD: American Association of Blood Banks; 1995:163-192.

9. Moulds JM, Nowicki S, Moulds JJ, Nowicki BJ. Human blood groups: incidental receptors for viruses and bacteria. Transfusion. 1996;36 (4):362-374. doi:10.1046/j.1537-2995.1996.36496226154.x 
10. Cartron JP, Prou O, Luilier M, Soulier JP. Susceptibility to invasion by Plasmodium falciparum of some human erythrocytes carrying rare blood group antigens. $\mathrm{Br} J$ Haematol. 1983;55(4):639-647. doi:10.1111/j.1365-2141.1983.tb02846.x

11. Pasvol G, Chasis JA, Mohandas N, Anstee DJ, Tanner MJ, Merry AH. Inhibition of malarial parasite invasion by monoclonal antibodies against glycophorin A correlates with reduction in red cell membrane deformability. Blood. 1989;74(5):1836-1843. doi:10. 1182/blood.V74.5.1836.1836

12. Hadley TJ, Klotz FW, Miller LH. Invasion of erythrocytes by malaria parasites: a cellular and molecular overview. Annu Rev Microbiol. 1986;40(1):451-477. doi:10.1146/annurev.mi.40.100186.002315

13. Allaway GP, Burness AT. Site of attachment of encephalomyocarditis virus on human erythrocytes. J Virol. 1986;59(3):768-770. doi:10. 1128/jvi.59.3.768-770.1986

14. Groves JD, Tanner MJ. The effects of glycophorin A on the expression of the human red cell anion transporter (band 3) in Xenopus oocytes. J Membr Biol. 1994;140(1):81-88. doi:10.1007/BF00234488

15. Reid ME. MNS blood group system: a review. Immunohematology. 2009;25(3):95-101. doi:10.21307/immunohematology-2019-240

16. Postoway N, Anstee DJ, Wortman M, Garratty G. A severe transfusion reaction associated with anti-EnaTS in a patient with an abnormal alpha-like red cell sialoglycoprotein. Transfusion. 1988;28 (1):77-80. doi:10.1046/j.1537-2995.1988.28188127961.x

17. Pavone BG, Billman R, Bryant J, Sniecinski I, Issitt PD. An autoanti-Ena, inhibitable by MN sialoglycoprotein. Transfusion. 1981;21 (1):25-31. doi:10.1046/j.1537-2995.1981.21181127479.x

18. Garratty G, Arndt P, Domen R, et al. Severe autoimmune hemolytic anemia associated with IgM warm auto-antibodies directed against determinants on or associated with glycophorin A. Vox Sang. 1997;72 (2):124-130. doi:10.1046/j.1423-0410.1997.7220124.x

19. Cleghorn TE. MNSs gene frequencies in English blood donors. Nature. 1960;187(4738):701. doi:10.1038/187701a0

20. Race RR, Sanger R. Blood Groups in Man. 6th ed. Oxford, United Kingdom: Blackwell Scientific Publications; 1975.

21. Thakral B, Saluja K, Sharma RR, Marwaha N. Phenotype frequencies of blood group systems (Rh, Kell, Kidd, Duffy, MNS, P, Lewis, and Lutheran) in north Indian blood donors. Transfus Apher Sci. 2010;43 (1):17-22. doi:10.1016/j.transci.2010.05.006
22. Owaidah AY, Naffaa NM, Alumran A, Alzahrani F. Phenotype frequencies of major blood group systems (Rh, kell, Kidd, Duffy, MNS, $\mathrm{p}$, Lewis, and Lutheran) among blood donors in the eastern region of Saudi Arabia. J Blood Med. 2020;11:59-65. doi:10.2147/JBM. S236834

23. AlHamdan NA, AlMazrou YY, AlSwaidi FM, Choudhry AJ Premarital screening for thalassemia and sickle cell disease in Saudi Arabia. Genet Med. 2007;9(6):372-377. doi:10.1097/GIM.0b01 3e318065a9e8

24. Memish ZA, Owaidah TM, Saeedi MY. Marked regional variations in the prevalence of sickle cell disease and $\beta$-thalassemia in Saudi Arabia: findings from the premarital screening and genetic counseling program. J Epidemiol Glob Health. 2011;1(1):61-68. doi:10.1016/j. jegh.2011.06.002

25. Thedsawad A, Taka O, Wanachiwanawin W. Prevalence and clinical significances of red cell alloimmunization and red cell bound immunoglobulin $G$ in polytransfused patients with thalassemias. Hematology. 2019;24(1):208-214. doi:10.1080/16078454.2018.15 49818

26. Halawani AJ, Saboor M, Abu-Tawil HI, Mahzari AA, Mansor AS, Bantun F. Prevalence of Duffy blood group antigens and phenotypes among Saudi blood donors in Southwestern Saudi Arabia. Clin Lab. 2021;67(1). doi:10.7754/Clin.Lab.2020.200505

27. Yazdanbakhsh K, Ware RE, Noizat-Pirenne F. Red blood cell alloimmunization in sickle cell disease: pathophysiology, risk factors, and transfusion management. Blood. 2012;120(3):528-537. doi:10.1182/ blood-2011-11-327361

28. Halawani AJ, Arjan AH. ABO, RH, and KEL1 antigens, phenotypes and haplotypes in Southwestern Saudi Arabia. Clin Lab. 2021;67(2) doi:10.7754/Clin.Lab.2020.200633

29. Halawani AJ, Saboor M, Abu-Tawil HI, et al. The frequencies of Kidd blood group antigens and phenotypes among Saudi blood donors in Southwestern Saudi Arabia. Saudi J Biol Sci. 2021. doi:10.1016/j.sjbs.2021.08.081

30. Nathalang O, Kuvanont S, Punyaprasiddhi P, Tasaniyanonda C, Sriphaisal T. A preliminary study of the distribution of blood group systems in Thai blood donors determined by the gel test. Southeast Asian J Trop Med Public Health. 2001;32(1):204-207.
International Journal of General Medicine

\section{Publish your work in this journal}

The International Journal of General Medicine is an international, peer-reviewed open-access journal that focuses on general and internal medicine, pathogenesis, epidemiology, diagnosis, monitoring and treatment protocols. The journal is characterized by the rapid reporting of reviews, original research and clinical studies across all disease areas. The manuscript management system is completely online and includes a very quick and fair peer-review system, which is all easy to use. Visit http://www.dovepress.com/ testimonials.php to read real quotes from published authors. 